\title{
Development and evaluation of improved lines with broad-spectrum resistance to rice blast using nine resistance genes
}

\author{
Haichao Jiang ${ }^{\dagger}$, Zhi Li ${ }^{\dagger}$, Jia Liu', Zhikang Shen, Guanjun Gao, Qinglu Zhang and Yuqing He ${ }^{*}$ (D)
}

\begin{abstract}
Background: Rice blast disease is a major restriction in rice production. That is usually managed using chemical pesticides, which are expensive in terms of cost and environment hazards. Use of blast-resistance genes to develop resistant varieties may therefore be a more economical and environmentally friendly method for effective control.

Results: In this study, we improved the blast resistance of four sterile lines, Y58S, GuangZhan63S (GZ63), C815S and HD9802S, by introgression of 9 cloned broad-spectrum blast resistance genes Pi37, Pit, Pid3, Pigm, Pi36, Pi5, Pi54, Pikm and Pb1. Through molecular marker-assisted selection and backcross breeding, 31 single-gene derived lines and 20 double-gene combination lines were obtained. When infected naturally, single-gene lines with Pigm or Pid3 showed significantly enhanced resistance during whole growth period relative to their recurrent parent. Singlegene lines with Pi37, Pi5, Pit, Pi36, Pi54 or Pikm showed significantly enhanced resistance in some of the four backgrounds. No obviously enhanced resistance was observed in single-gene line with $P b 1$ for the whole growth period. Compared with recurrent parents, most of the double-gene lines showed improved resistance. Among these double-gene lines, lines with Pi37/Pid3, Pi5/Pi54, Pi54/Pid3 or Pigm/Pi37, exhibited significantly enhanced resistance and observable additive effects.
\end{abstract}

Conclusions: Two blast resistance genes, Pigm and Pid3, showed significantly enhanced resistance for the whole rice growth period, and six blast resistance genes Pi37, Pi5, Pit, Pi36, Pi54 or Pikm showed significantly enhanced resistance for some of the four backgrounds. Double-gene lines with Pi37/Pid3, Pi5/Pi54, Pi54/Pid3 and Pigm/Pi37 exhibited significantly enhanced resistance and observable additive effects. These lines could be used in rice hybrid and production.

Keywords: Rice, Blast resistance, Marker assisted selection, Gene pyramiding, Natural infection

\section{Introduction}

Rice (Oryza sativa) is a staple food crop for more than $50 \%$ of the world's population. Rice blast disease is a major restriction on rice production in both tropical and temperate countries, and it is also a major obstacle to hybrid rice production in China due to the relatively narrow genetic base of hybrid rice and the increased use of nitrogen fertilizer (Liu et al. 2010a). The average blast infected area was more than 3.8 million hectares in 1982-1985, with yield losses of several million tons (Sun et al. 1999). In

\footnotetext{
* Correspondence: yqhe@mail.hzau.edu.cn

${ }^{\dagger}$ Haichao Jiang, Zhi Li and Jia Liu contributed equally to this work. National Key Laboratory of Crop Genetic Improvement, National Center of Plant Gene Research (Wuhan) and National Center of Crop Molecular Breeding, Huazhong Agricultural University, Wuhan 430070, China
}

1993, a yield loss of 1.1 million tons was recorded in Southern China alone. Conventional methods of controlling blast depended on fungicides, which generate additional costs in rice production and chemical contamination of the environment and food. The development and use of resistant varieties with the major resistance genes is therefore one of the most economical and effective ways to control this disease (Koide et al. 2009; Deng et al. 2017).

To date, over 100 blast resistant genes or quantitative trait loci (QTL) have been identified (Su et al. 2015; Vasudevan et al. 2016; Zheng et al. 2016; Xiao et al. 2017). Among them, 35 genes have been cloned (Wang et al. 2017). Many of these resistance genes are clustered on rice chromosomes 6,11 and 12. Notably, at least 11 
resistance genes-including Pi2, Pi9, Piz, Pizt, Pigm, Pi22, Pi25, Pi26, Pi40, Pi42 and Pi50-are concentrated in the short-arm region near the centromere of chromosome 6. Blast resistance gene Pi37 was mapped from rice cultivar St. No. 1, which encoded a nucleotide-binding site leucine-rich repeat (NBS-LRR) protein on rice chromosome 1 (Chen et al. 2005; Lin et al. 2007). The Pit gene was originally identified in cultivar K59 (Hayashi and Yoshida 2009); it was a member of the NBS-LRR family of $\mathrm{R}$ genes. The Pid3 gene was identified by genome-wide comparison of paired NBS-LRR genes and their pseudogene alleles between the two sequenced rice genomes 9311 and Nipponbare, and an allelic Pid3 in Digu was identified on chromosome 6 (Shang et al. 2009). The broad-spectrum resistance gene Pigm was identified from the native Chinese variety Gumei 4 . PigmR confers broad-spectrum resistance, whereas PigmS competitively attenuates PigmR homodimerization to suppress resistance. The expression of PigmS that triggered PigmR-mediated resistance is subjected to tight epigenetic regulation (Deng et al. 2009; Deng et al. 2017). Pi36 identified in an indica cultivar, Q61, was mapped on chromosome 8 and encoded as an NBS-LRR protein (Liu et al. 2005; Liu et al. 2010b). The Pi5 gene was identified from RIL260, and the resistance of Pi5 to Magnaporthe oryzae requires the presence of the two coiled-coil NBS-LRR genes Pi5-1 and Pi5-2 (Lee et al. 2009). Pi54 was originally identified from the rice variety Tetep and was mapped on chromosome 11 with two tightly linked simple sequence repeat (SSR) markers TRS26, TRS33 and a functional marker Pi54-MAS (Sharma et al. 2005; Ramkumar et al. 2011). Pi54 was $\sim 2.5 \mathrm{Mb}$ away from the Pik locus on rice chromosome 11 (Sharma et al. 2010). It had been reported that the Pik locus was actually a cluster of genes including Pikm, Pik-h and Pik-p presenting on rice chromosome 11 (Ashikawa et al. 2008; Zhai et al. 2014; Yuan et al. 2011). Pikm-specific rice blast resistance is conferred by a combination of two genes, Pikm1-TS and Pikm2-TS, with an NBS-LRR (Ashikawa et al. 2010). The $\mathrm{Pb} 1$ gene derived from an indica cultivar, Modan, and is characterized by durability of resistance and adult/panicle blast resistance (Hayashi et al. 2010; Table 1).

Marker-assisted selection (MAS) is a highly efficient breeding approach that could offer an opportunity to select the targeted gene rapidly and precisely (Tanksley et al. 1989). It is a promising method to provide broad-spectrum and durable rice blast resistance through gene or QTL pyramiding (Tabien et al. 2002). Recently, the development of near-isogenic lines or the pyramiding of different resistance genes has been applied in blast resistance breeding programs by marker-assisted selection. Three blast resistance genes (Pi1, Pi2 and D12) were introduced into rice variety Jin23B (Jiang et al. 2012), and Pi9, Pizt and Pi54 were recently introduced into rice variety $07 \mathrm{GY} 31$ by marker assisted backcross breeding (Xiao et al. 2017). Evaluation of blast resistance suggested that single or polygene pyramid lines showed significantly enhanced resistance relative to control.

Y58S, GZ63S, C815S and HD9802S are elite rice varieties in rice production in China, but these four varieties and their derived hybrids are highly susceptible to blast. Improvement of blast resistance in Y58S, GZ63S, C815S and HD9802S is therefore critical in utilizing the hybrids in rice production in China.

In this study, 9 cloned blast resistance genes, Pi37, Pit, Pid3, Pigm, Pi36, Pi5, Pi54, Pikm and Pb1, were introgressed into male sterile lines including Y58S, GZ63S, C815S and HD9802S. Our objective was to evaluate the natural resistance performance of these cloned blast resistance genes and to improve hybrid rice blast resistance in production.

\section{Materials and methods}

\section{Plant materials}

Nine rice varieties, Q1333 (Pi37), K59 (Pit), Digu (Pid3), Gumei4 (Pigm), Q61 (Pi36), RIL260 (Pi5), Tsuyuake (Pikm), Tetep (Pi54) and Modan (Pb1), were used as donors of the cloned resistance genes (Table 1). Four male sterile rice lines (Y58S, GZ63S, C815S and HD9802S),

Table 1 List of blast resistance genes using in this study

\begin{tabular}{lllll}
\hline Gene & Chromosome & Encoding protein & Donor & Reference \\
\hline Pi37 & 1 & NBS-LRR & St. No. 1 & Lin et al. 2007 \\
Pit & 1 & NBS-LRR & K59 & Hayashi and Yoshida 2009 \\
Pid3 & 6 & NBS-LRR & Digu & Shang et al. 2009 \\
Pigm & 6 & NBS-LRR & Gumei4 & Deng et al. 2009 \\
Pi36 & 8 & NBS-LRR & Q61 & Liu et al. 2005 \\
Pi5 & 9 & NBS-LRR & IRL260 & Lee et al. 2009 \\
Pi54 & 11 & NBS-LRR & Tetep & Sharma et al. 2005 \\
Pikm & 11 & NBS-LRR & Tsuyuake & Ashikawa et al. 2008 \\
Pb1 & 11 & NBS-LRR & Modan & Hayashi et al. 2010 \\
\hline
\end{tabular}


which are the main female parent of indica hybrid rice in southern China, were used as the recurrent parents. The $\mathrm{F}_{1}, \mathrm{BC}_{1} \mathrm{~F}_{1}, \mathrm{BC}_{2} \mathrm{~F}_{1}$ and $\mathrm{BC}_{3} \mathrm{~F}_{1}$ lines were derived from crosses between the recurrent parents and the donor parents. The $\mathrm{BC}_{1} \mathrm{~F}_{2}$ and $\mathrm{BC}_{2} \mathrm{~F}_{2}$ populations were developed from the $\mathrm{BC}_{1} \mathrm{~F}_{1}$ and $\mathrm{BC}_{2} \mathrm{~F}_{1}$ resistant individuals. These populations were used for genetic and phenotypic analysis. The susceptible variety $\mathrm{CO} 39$ was used as a negative control.

\section{DNA extraction and genotyping}

For MAS during each generation, DNA was isolated from the leaf tissues of the parent, $\mathrm{BC}_{\mathrm{n}} \mathrm{F}_{1}, \mathrm{BC}_{\mathrm{n}} \mathrm{F}_{2}$ and $\mathrm{F}_{2}$ plants using the CTAB method. In the MAS system, Pit was detected using SSR marker RM10125 and InDel marker RMLTJ-3; Pi37 was detected using SSR marker RM11726 and InDel marker RMLJ-1; and Pigm was detected using InDel marker Pi2-4 and SSR markers HC26 and HC3. The flanking InDel marker RML3J-1 and SSR marker RM19951 were used to detected Pid3; the SSR marker RM22385 and InDel marker RMLJ-2 were used to detected Pi36; and two SSR markers, RM24019 and RM24034, and one InDel marker, RMLJ-7, were used to detected Pi5. Three tightly linked
SSR markers RM27150, RM27181 and RM27189 were used to confirm gene Pi54. Two tightly linked SSR markers RM26998 and RM26964 were used to confirm Pb1. SSR marker RM224 and InDel marker RMLMJ-1 were used to confirm Pikm (Additional file 1: Table S1). The InDel markers RMLTJ-3, RMLJ-1, Pi2-4, RML3J-1, RMLJ-2, RMLJ-7 and RMLMJ-1 were designed based on sequence alignments of the two genome references of Nipponbare and 93-11 (Additional file 1: Table S1). The SSR analysis was carried out essentially according to the procedures described by Wu and Tanksley (1993).

\section{Crossing and selection scheme}

Q1333 (Pi37), K59 (Pit), Digu (Pid3), Gumei4 (Pigm), Q61 (Pi36), RIL260 (Pi5), Tsuyuake (Pikm), Tetep (Pi54) and Modan $(\mathrm{Pb1})$ were crossed separately with Y58S, GZ63S, C815S and HD9802S, and their $F_{1}$ hybrids were backcrossed with Y58S, GZ63S, C815S and HD9802S to obtain the $\mathrm{BC}_{1} \mathrm{~F}_{1}$ populations (Fig. 1). Markers closely linked with the blast resistance genes were used to check the target genes among the above $\mathrm{BC}_{1} \mathrm{~F}_{1}$ populations (Fig. 1; Fig. 2a). Twenty plants with the target genes from each $\mathrm{BC}_{1} \mathrm{~F}_{1}$ population were selected to backcross with the corresponding parents up to $\mathrm{BC}_{3} \mathrm{~F}_{1}$. From each

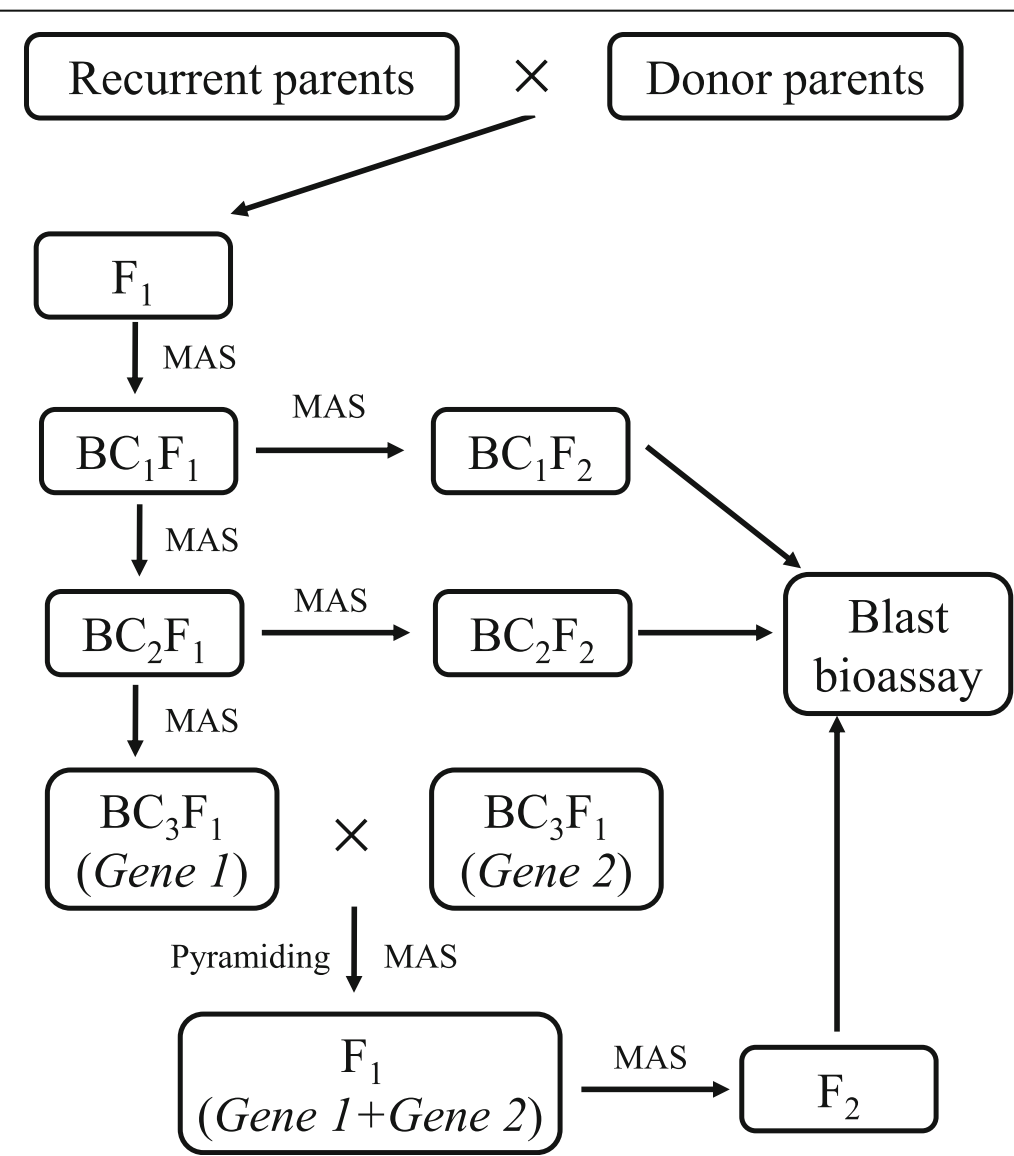

Fig. 1 Strategy to develop improved populations and resistance identification 


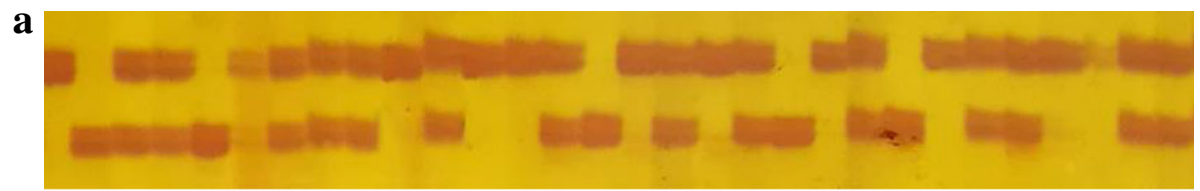

$12233455 \quad 6 \quad 7 \quad 8 \quad 9101112131415161718192021222324252627282930$

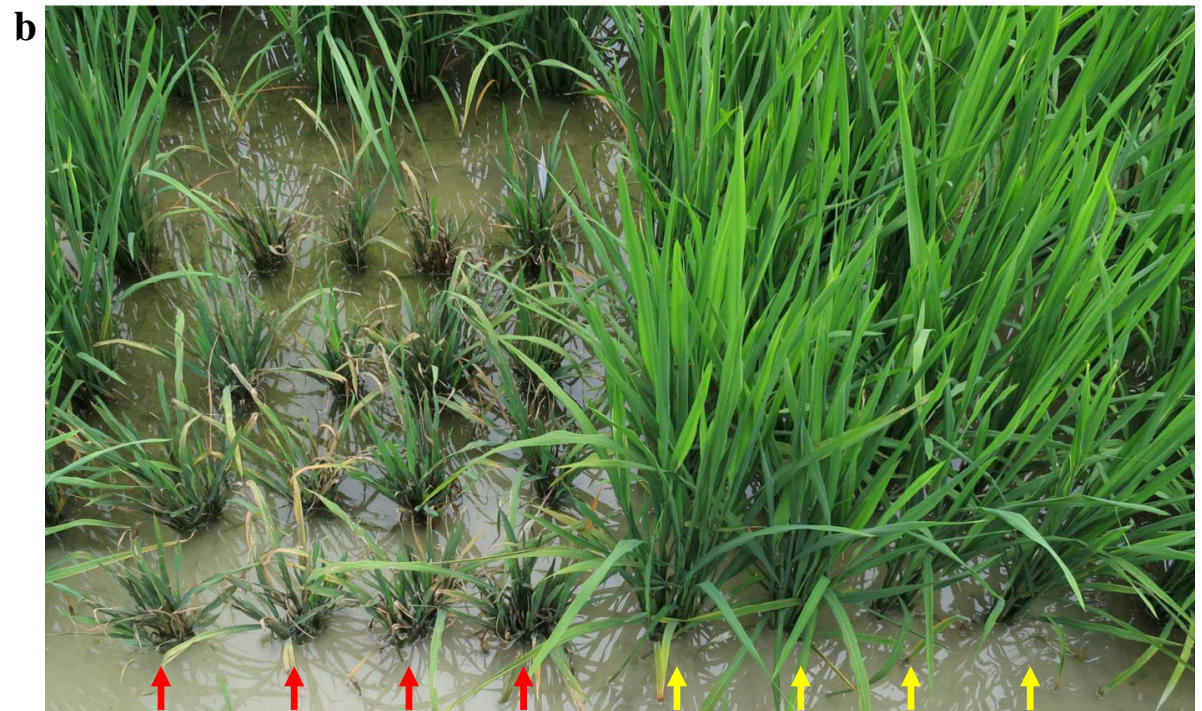

Fig. 2 Identification of improved blast resistant lines with MAS. a PCR amplification of the marker LJ3-1 for blast resistance gene Pid3 in the $\mathrm{BC}_{2} \mathrm{~F}_{2}$ population with the background of GZ63S. Lines 1, 2 and 3 are Digu (resistance homozygous), GZ63S (infected homozygous) and heterozygous (Digu/GZ63S), respectively. b Red arrows indicate susceptible parents GZ63S, yellow arrows show the resistant lines carrying target gene Pid3

generation, plants carrying single gene Pi37, Pit, Pid3, Pigm, Pi36, Pi5, Pi54, Pikm and Pb1 in the background of Y58S, GZ63S, C815S and HD9802S were obtained. After selfing, the $\mathrm{BC}_{1} \mathrm{~F}_{2}$ and $\mathrm{BC}_{2} \mathrm{~F}_{2}$ populations were obtained, which were then used to evaluate the effects of individual genes in different backgrounds. In the $\mathrm{BC}_{3} \mathrm{~F}_{1}$ populations, two genes in the same background were crossed with each other, and then the $F_{1}$ hybrids and the corresponding $F_{2}$ population were obtained (Fig. 1).

\section{Scoring rice blast}

The $\mathrm{BC}_{1} \mathrm{~F}_{2}, \mathrm{BC}_{2} \mathrm{~F}_{2}$ and $\mathrm{F}_{2}$ families of the blast resistance genes Pi37, Pit, Pid3, Pigm, Pi36, Pi5, Pi54, Pikm and $\mathrm{Pb} 1$ in the background of Y58S, GZ63S, C815S and HD9802S were planted in a randomized complete block design in 2014, 2015 and 2016 in Xianfeng, Hubei Province, China. Xianfeng is a mountainous area at an altitude of $600 \mathrm{~m}$, with an average temperature of approximately $25^{\circ} \mathrm{C}$, showing high humidity and heavy fog annually. The tests were performed in three replications. In each replication, each of the plots consisted of 8 rows with 12 plants per row at a planting density of $16 \mathrm{~cm}$ between plants and $26.5 \mathrm{~cm}$ between rows. To adequately induce blast disease infection, the diseased straws collected the previous year were sown evenly in each plot and the highly susceptible variety, $\mathrm{CO} 39$, was planted at both sides of each row and around the population. Field management essentially followed normal agricultural practices with the exception of not using bactericides.

All the plants were scored for leaf blast at the tillering stage and were recorded for neck blast severity at maturity. The most seriously infected leaf among the top two or three new leaves was scored for each plant at the tillering stage, as determined using the $0-9$ scale rating system from IRRI (2002). Neck blast severity was recorded as a percentage of the infection on the neck of the rice panicle at physiological maturity. The number of panicles showing symptoms of neck blast was expressed as percent infection.

\section{Statistical analysis}

The data obtained from the experiments were statistically analyzed using analysis of variance (ANOVA) of respective experimental designs. Phenotypic and genotypic data were collected for each individual plant in the $\mathrm{BC}_{1} \mathrm{~F}_{2}$ and $\mathrm{BC}_{2} \mathrm{~F}_{2}$ populations. The additive effect (A), dominant effect (D) and phenotypic variation explained (PVE) of the resistance genes were analyzed in a segregated population between different genotypes at $P=0.05$ 
Table 2 Phenotypic average value of recurrent parents and donor parents in 2014, 2015 and 2016

\begin{tabular}{|c|c|c|c|c|c|c|c|c|c|c|c|c|c|c|}
\hline & & \multicolumn{4}{|c|}{ Recurrent parents } & \multicolumn{9}{|c|}{ Donor parents } \\
\hline & & Y58S & GZ63S & C815S & HD9802S & $\begin{array}{l}\mathrm{K} 59 \\
\text { (Pit) }\end{array}$ & $\begin{array}{l}\text { Tsuyuake } \\
(\text { Pikm) }\end{array}$ & $\begin{array}{l}\text { Modan } \\
(P b 1)\end{array}$ & $\begin{array}{l}\text { RIL260 } \\
\text { (Pi5) }\end{array}$ & $\begin{array}{l}\text { Q61 } \\
\text { (Pi36) }\end{array}$ & $\begin{array}{l}\text { Q1333 } \\
\text { (Pi37) }\end{array}$ & $\begin{array}{l}\text { Gumei4 } \\
\text { (Pigm) }\end{array}$ & $\begin{array}{l}\text { Digu } \\
\text { (Pid3) }\end{array}$ & $\begin{array}{l}\text { Tetep } \\
\text { (Pi54) }\end{array}$ \\
\hline \multirow[t]{2}{*}{2014} & LB & 6.99 & 7.42 & 6.90 & 6.50 & 5.70 & 4.40 & 4.60 & 5.70 & 8.50 & 3.80 & 2.98 & 3.10 & 3.02 \\
\hline & $\mathrm{NB}(\%)$ & 98.71 & 98.83 & 99.08 & 98.17 & 97.93 & 98.85 & 98.93 & 97.10 & 100.00 & 21.11 & 3.00 & 3.04 & 2.05 \\
\hline \multirow[t]{2}{*}{2015} & LB & 6.57 & 7.75 & 6.38 & 6.68 & 2.33 & 2.67 & 3.30 & 1.75 & 7.67 & 3.01 & 1.33 & 3.08 & 1.00 \\
\hline & $\mathrm{NB}(\%)$ & 95.28 & 100.00 & 93.15 & 100.00 & 100.00 & 100.00 & 100.00 & 79.08 & 40.17 & 35.95 & 36.99 & 7.97 & 1.00 \\
\hline \multirow[t]{2}{*}{2016} & LB & 6.53 & 7.02 & 6.98 & 6.45 & 3.92 & 4.08 & 3.17 & 4.83 & 6.75 & 1.99 & 1.92 & 1.17 & 2.02 \\
\hline & NB(\%) & 100.00 & 100.00 & 100.00 & 100.00 & 100.00 & 100.00 & 100.00 & 78.06 & 62.03 & 5.99 & 5.04 & 7.97 & 1.00 \\
\hline
\end{tabular}

$L B$ Leaf blast, $N B$ Neck blast

and 0.01 significance. The analyses of these statistical parameters were carried out using the statistical software SPSS 20.0.

\section{Results}

Improved blast resistance materials obtained through MAS

Seven blast resistance genes, Pi37, Pit, Pid3, Pigm, Pi36, Pi5, Pi54, were introgressed into Y58S, GZ63S, C815S and HD9802S separately following a recurrent backcrossing procedure, combined with MAS as described in Fig. 1. In addition, Pikm for blast resistance was introgressed into C815S and HD9802S, and Pb1 for blast resistance was introgressed into GZ63S, using the marker-assisted backcross breeding method (Fig. 1). Thirty-one $\mathrm{BC}_{1} \mathrm{~F}_{2}, \mathrm{BC}_{2} \mathrm{~F}_{2}$ and $\mathrm{BC}_{3} \mathrm{~F}_{1}$ lines with single resistance genes were obtained.

The improved lines containing a single resistance gene in $\mathrm{BC}_{3} \mathrm{~F}_{1}$ progenies were intercrossed with each other to pyramid two resistance genes. The $\mathrm{F}_{1}$ plants containing two resistance genes were selected through the linked DNA markers of each target gene. Two gene pyramiding lines were also obtained, including Y58S (Pi37/Pi54), Y58S (Pi5/Pi37), Y58S (Pi5/Pigm), Y58S (Pigm/Pi54), Y58S (Pi37/Pid3), Y58S (Pi37/Pigm) in Y58S background, GZ63S (Pit/Pigm), GZ63S (Pit/Pb1), GZ63S (Pi5/Pit), GZ63S (Pi5/Pi37), GZ63S (Pi36/Pb1), GZ63S (Pi5/Pigm), GZ63S (Pi36/Pid3), GZ63S (Pb1/Pigm), GZ63S (Pi5/ Pi54), GZ63S (Pid3/Pi54) in GZ63S background, C815S (Pit/Pigm), C815S (Pi5/Pit), C815S (Pi5/Pigm) and C815S (Pi37/Pigm) in C815S background (Fig. 1).

\section{Blast resistance of the donor parents and recurrent parents}

Four recurrent parents and nine donor parents were planted in Xianfeng in 2014, 2015 and 2016. Each variety was planted in three replications with 12 plants per plot. The resistance scores for leaf blast for Y58S were 6.99, 6.57 and 6.53, and the percentages of infection for neck blast were $98.71 \%, 95.28 \%$ and $100 \%$ in 2014, 2015 and 2016, respectively. The resistance scores for leaf blast for
GZ63 were 7.42, 7.75 and 7.02 and the percentages of infection for neck blast were $98.83 \%, 100 \%$ and $100 \%$ in 2014, 2015 and 2016, respectively. At the disease nursery of Xianfeng, the resistance scores for leaf blast for C815S and HD9802S were 6.90, 6.38 and 6.98 and 6.50, 6.68 and 6.45 , and the percentages of infection for neck blast were $99.08 \%, 93.15 \%$ and $100 \%$ and $98.17 \%, 100 \%$ and 100\%, in 2014, 2015 and 2016, respectively. Four recurrent parents, Y58S, GZ63S, C815S and HD9802S, showed medium or high susceptibility to leaf blast at the tillering stage and high susceptibility to neck blast at maturation in Xianfeng in 2014, 2015 and 2016 (Table 2). These results illustrated a serious loss of blast resistance in the main hybrid rice, and it is imperative to improve the blast resistance in hybrid rice in China.

The resistance scores for leaf blast at the tillering stage and the percentage of infection for neck blast at maturation were 5.70 and $97.93 \%$ for K59; 4.40 and $98.85 \%$ for Tsuyuake; 4.60 and $98.93 \%$ for Modan; 5.70 and $97.10 \%$ for RIL260; 8.50 and 100.00\% for Q61; 3.80 and 21.11\% for Q1333; 2.98 and 3.00\% for Gumei4; 3.10 and 3.04\% for Digu; 3.02 and $2.05 \%$ for Tetep, respectively, in 2014 (Table 2). The resistance scores for leaf blast at tillering stage for these nigh varieties were $2.33,2.67,3.30,1.75$, $7.67,3.01,1.33,3.08$ and 1.00, respectively, in 2015, and $3.92,4.08,3.17,4.83,6.75,1.99,1.92,1.17$ and 2.02, respectively, in 2016 (Table 2). The percentages of infection for neck blast at maturity stage for the nine variety were $100.00 \%, 100.00 \%, 100.00 \%, 79.08 \%, 40.17 \%$, $35.95 \%, 36.99 \%, 7.97 \%$ and $1.00 \%$, respectively in 2015 and $100.00 \%, 100.00 \%, 100.00 \%, 78.06 \%, 62.03 \%, 5.99 \%$, $5.04 \%, 7.97 \%$ and $1.00 \%$, respectively in 2016 (Table 2). These results showed that Gumei4, Digu, Tetep and Q1333 had high resistance to leaf blast and neck blast during these 3 years. K59, Tsuyuake, Modan and RIL260 had high resistance to leaf blast in 2015 and medium resistance to leaf blast in 2014 and 2016, but were susceptible to neck blast for all 3 years. The resistance scores of Q61 to leaf blast and percentage of infection for neck blast showed that the variety was susceptible to both leaf blast and neck blast. 
Table 3 Broad-spectrum resistance of different resistance genes over whole growth period in 2014 and 2015 in Xianfeng

\begin{tabular}{|c|c|c|c|c|c|c|c|c|c|c|c|c|c|}
\hline \multirow[t]{3}{*}{ Gene } & \multirow{3}{*}{$\begin{array}{l}\text { Recurrent } \\
\text { parent }\end{array}$} & \multicolumn{6}{|c|}{ Leaf Blast } & \multicolumn{6}{|c|}{ Neck Blast } \\
\hline & & \multicolumn{3}{|c|}{2014} & \multicolumn{3}{|l|}{2015} & \multicolumn{3}{|l|}{2014} & \multicolumn{3}{|l|}{2015} \\
\hline & & $\bar{A}$ & $D$ & PVE (\%) & $\bar{A}$ & $\mathrm{D}$ & PVE (\%) & $A$ & $D$ & PVE (\%) & $A$ & $\mathrm{D}$ & PVE (\%) \\
\hline \multirow[t]{4}{*}{ Pi5 } & Y58S & -0.05 & -0.10 & 0.41 & -0.02 & 0.09 & 0.94 & - & - & - & 0.00 & 0.00 & 0.00 \\
\hline & GZ63S & 0.00 & 0.00 & 0.00 & -0.72 & 0.15 & $13.81^{\mathrm{a}}$ & 0.00 & 0.00 & 0.00 & -0.13 & -0.14 & $10.38^{\mathrm{a}}$ \\
\hline & C815S & -0.95 & -0.82 & $39.69^{b}$ & / & / & / & - & - & - & / & / & I \\
\hline & HD9802S & -0.26 & -0.07 & 3.84 & -0.69 & -0.45 & $20.78^{b}$ & - & - & - & -0.05 & -0.14 & 2.19 \\
\hline \multirow[t]{4}{*}{ Pi36 } & Y58S & -0.03 & -0.11 & 0.55 & -0.27 & 0.07 & 4.32 & 0.00 & 0.00 & 0.00 & -0.03 & -0.04 & 0.11 \\
\hline & GZ63S & 0.04 & -0.68 & 2.48 & -0.23 & 0.15 & 8.35 & 0.00 & 0.00 & 0.00 & 0.00 & 0.00 & 0.00 \\
\hline & C815S & 0.25 & -0.08 & 4.40 & -0.33 & 0.10 & 3.76 & 0.00 & 0.00 & 0.00 & -0.02 & 0.02 & $5.81^{\mathrm{a}}$ \\
\hline & HD9802S & -0.33 & 0.18 & 5.75 & 0.10 & -0.10 & 0.08 & 0.00 & 0.00 & 0.00 & -0.04 & 0.01 & 0.54 \\
\hline \multirow[t]{4}{*}{ Pi37 } & Y58S & -0.14 & -0.10 & 3.10 & -0.58 & -0.04 & $7.17^{\mathrm{a}}$ & -0.19 & -0.10 & $9.73^{\mathrm{a}}$ & -0.07 & -0.06 & $6.06^{\mathrm{a}}$ \\
\hline & GZ63S & -0.61 & -0.67 & $13.50^{\mathrm{b}}$ & / & / & / & -0.36 & -0.44 & $59.85^{b}$ & / & / & / \\
\hline & C815S & 0.00 & 0.00 & 0.00 & -0.88 & 0.74 & $21.06^{b}$ & - & - & - & -0.05 & 0.06 & 0.74 \\
\hline & HD9802S & / & / & / & -0.04 & -0.16 & 0.18 & / & / & / & 0.00 & 0.00 & 0.00 \\
\hline \multirow[t]{4}{*}{ Pigm } & Y58S & -1.46 & -1.09 & $30.54^{b}$ & -0.64 & -0.96 & $9.25^{\mathrm{a}}$ & -0.40 & -0.36 & $46.44^{b}$ & -0.39 & -0.23 & $41.04^{b}$ \\
\hline & GZ63S & / & / & I & -0.18 & -0.05 & 1.53 & / & / & / & -0.30 & -0.33 & $26.00^{b}$ \\
\hline & C815S & -0.12 & 0.02 & 0.84 & -0.48 & -0.06 & $6.47^{\mathrm{a}}$ & -0.17 & -0.08 & $7.88^{\mathrm{a}}$ & -0.28 & -0.18 & $33.00^{b}$ \\
\hline & HD9802S & -0.11 & 0.05 & 0.75 & -1.75 & -1.20 & $42.84^{b}$ & - & - & - & -0.38 & -0.30 & $39.82^{b}$ \\
\hline \multirow[t]{4}{*}{ Pi54 } & Y58S & -0.27 & -0.13 & $6.18^{\mathrm{a}}$ & -0.83 & -0.39 & $23.09^{b}$ & -0.18 & -0.19 & $15.81^{\mathrm{b}}$ & -0.30 & 0.16 & $30.13^{b}$ \\
\hline & GZ63S & 0.14 & 0.27 & 2.23 & -0.60 & -0.13 & $20.32^{b}$ & 0.01 & -0.05 & 0.35 & -0.13 & -0.03 & $12.17^{\mathrm{a}}$ \\
\hline & C815S & 0.21 & -0.07 & 2.91 & / & / & / & - & - & - & / & / & / \\
\hline & HD9802S & -0.08 & 0.01 & 0.28 & -0.44 & -0.43 & $6.38^{\mathrm{a}}$ & - & - & - & -0.28 & -0.03 & $30.88^{b}$ \\
\hline \multirow[t]{4}{*}{ Pid3 } & Y58S & -0.90 & -0.79 & $31.99^{b}$ & -1.23 & 0.42 & $17.76^{b}$ & -0.34 & -0.31 & $40.77^{b}$ & -0.38 & -0.22 & $64.61^{b}$ \\
\hline & GZ63S & -1.09 & -0.69 & $32.62^{b}$ & -1.66 & -1.53 & $75.48^{b}$ & -0.39 & -0.22 & $39.26^{b}$ & -0.38 & -0.35 & $64.38^{b}$ \\
\hline & C815S & -1.76 & -1.60 & $48.83^{b}$ & -0.69 & -0.51 & $17.88^{\mathrm{a}}$ & -0.35 & -0.05 & $25.65^{b}$ & -0.19 & 0.06 & $23.42^{b}$ \\
\hline & HD9802S & -0.67 & -0.58 & $36.41^{b}$ & -0.90 & 0.10 & $34.49^{b}$ & -0.30 & -0.01 & $35.19^{b}$ & -0.32 & 0.11 & $32.42^{b}$ \\
\hline \multirow[t]{4}{*}{ Pit } & Y58S & -0.09 & -0.41 & 3.23 & -0.18 & -0.50 & 4.22 & 0.00 & 0.00 & 0.00 & 0.00 & 0.00 & 0.00 \\
\hline & GZ63S & -0.13 & -0.23 & 2.26 & -0.69 & 0.47 & $9.74^{\mathrm{a}}$ & 0.00 & 0.00 & 0.00 & -0.01 & 0.00 & 7.71 \\
\hline & C815S & 0.18 & 0.08 & 3.14 & -0.14 & -0.03 & 1.78 & 0.00 & 0.00 & 0.00 & -0.05 & 0.03 & 1.82 \\
\hline & HD9802S & / & / & / & -0.54 & -0.51 & $13.03^{a}$ & / & I & / & -0.05 & 0.03 & 5.18 \\
\hline$P b 1$ & GZ63S & / & / & / & -0.02 & -0.36 & 0.12 & / & / & / & 0.00 & 0.00 & 0.00 \\
\hline \multirow[t]{2}{*}{ Pikm } & C815S & -1.61 & -1.18 & $53.44^{b}$ & / & / & / & 0.00 & 0.00 & 0.00 & / & / & / \\
\hline & HD9802S & -1.05 & -1.04 & $40.33^{b}$ & / & / & / & 0.00 & 0.00 & 0.00 & / & / & / \\
\hline
\end{tabular}

A Additive effect, D Dominant effect, PVE (\%) Phenotypic variation explained (\%); ${ }^{a}$ and ${ }^{\mathrm{b}}$ denote significance at the 0.05 and 0.01 probability levels, respectively. "-" indicates no date were collected, "I" indicates no materials under the background

\section{Blast resistance of the genes in different backgrounds}

Seven blast resistance genes (Pi37, Pit, Pid3, Pigm, Pi36, Pi5, Pi54) were introduced into four recurrent parents Y58S, GZ63S, C815S and HD9802S, one blast resistance gene $($ Pikm) was introduced into C815S and HD9802S, and one blast resistance gene $(\mathrm{Pb} 1)$ was introduced into GZ63S. The resistance to leaf blast and neck blast of single gene introduced lines was tested in 2014 and 2015 in Xianfeng. Pid3 showed greater resistance to leaf blast and neck blast in the background of Y58S, GZ63S, C815S and HD9802S than the control in 2014 and 2015
(Table 3; Fig. 2). Pigm showed significantly enhanced resistance to leaf blast in the background of Y58S, C815S and HD9802S in 2015, and it showed significantly enhanced resistance to neck blast in the background of Y58S, GZ63S, C815S and HD9802S in 2014 and 2015 (Table 3). Pi5 showed significantly enhanced resistance to leaf blast in the background of C815S in 2014 and in the background of GZ63S and HD9802S in 2015 and significantly enhanced resistance to neck blast in the background of GZ63S in 2015 (Table 3). Pi37 showed significantly enhanced resistance to leaf blast in the 

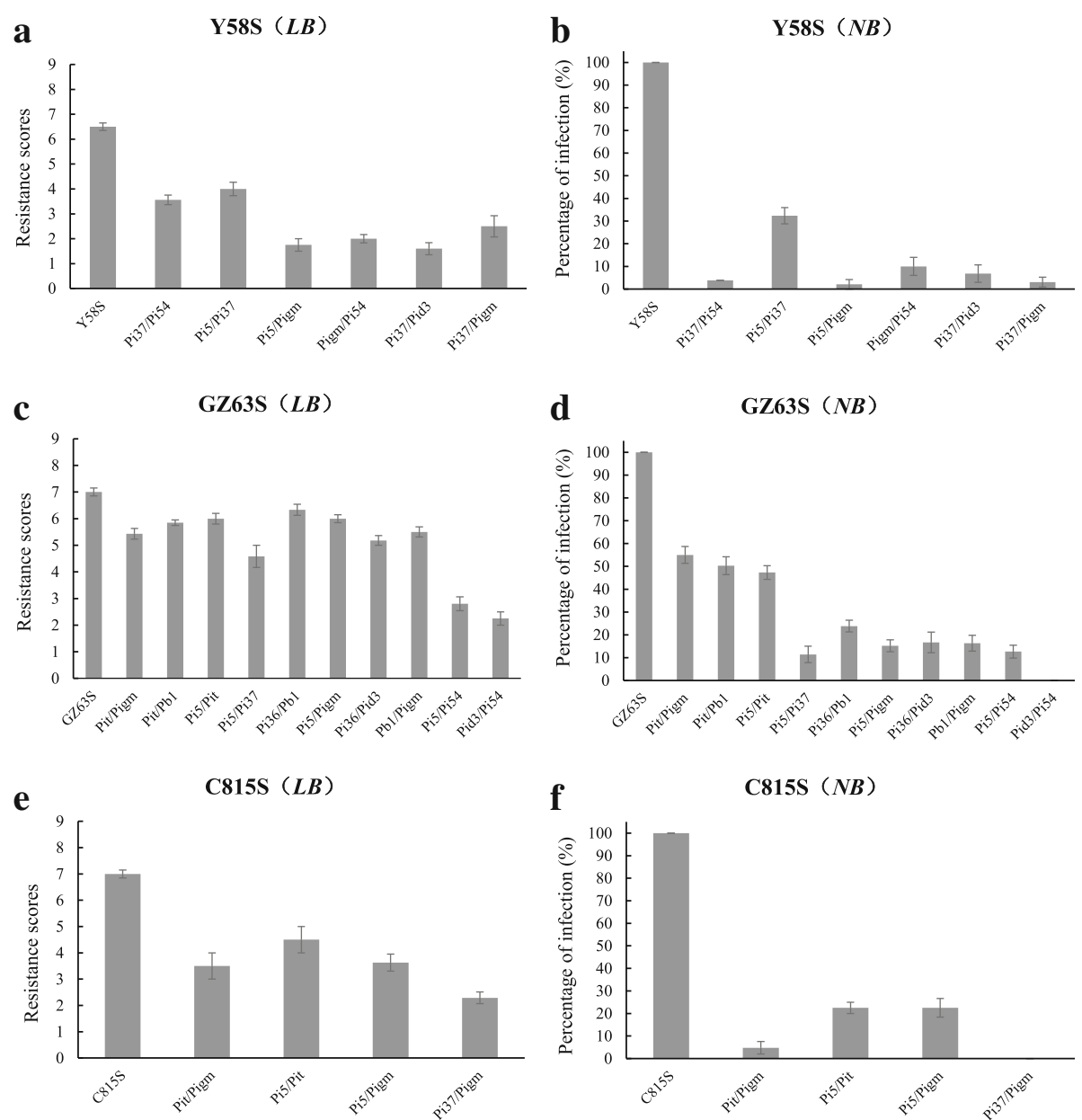

Fig. 3 Blast resistance scores of homozygous plants of pyramiding populations under different backgrounds. Shown are the average values for leaf blast (LB) in different pyramiding populations in the backgrounds Y58S (a) GZ63S (c) and C815S (e) and the average value of neck blast (NB) of different pyramiding populations in the backgrounds Y58S (b), GZ63S (d) and C815S (f)

background of GZ63S in 2014 and in the background of Y58S and C815S in 2015 and significantly enhanced resistance to neck blast in the background of Y58S and GZ63S in 2015. Pi54 showed significantly enhanced resistance to leaf and neck blast in the background of Y58S, GZ63S and HD9802S in 2015. Except for Pb1, all of the blast resistance genes showed enhanced resistance to leaf or neck blast in at least one background from a recurrent parent. However, the blast resistance of Pi5, Pi36 and Pit was not stable in most recurrent parents (Table 3).

\section{Blast resistance of two gene pyramiding lines}

Through MAS, 6, 10 and 4 lines with two-gene pyramiding in Y58S, GZ63S and C815S backgrounds were obtained. The blast resistance of two-gene pyramiding lines was scored for leaf blast at the tillering stage and neck blast at maturation in 2016. The resistance scores for leaf blast were 3.56 for Y58S (Pi37/Pi54), 4.00 for Y58S (Pi5/Pi37),
1.75 for Y58S (Pi5/Pigm), 2.00 for Y58S (Pigm/Pi54), 1.60 for Y58S (Pi37/Pid3), and 2.50 for Y58S (Pi37/Pigm), while the percentage of infection for neck blast was 3.88\%, $32.34 \%, 2.08 \%, 10.00 \%, 6.80 \%$ and $3.05 \%$, respectively (Fig. 3). At the tillering stage, the resistance scores for leaf blast for pyramiding lines GZ63S (Pit/Pigm), GZ63S (Pit/ Pb1), GZ63S (Pi5/Pit), GZ63S (Pi5/Pi37), GZ63S (Pi36/ Pb1), GZ63S (Pi5/Pigm), GZ63S (Pi36/Pid3), GZ63S (Pb1/ Pigm), GZ63S (Pi5/Pi54), GZ63S (Pid3/Pi54) were 5.42, $5.84,6.00,4.58,6.33,6.00,5.18,5.50,2.80$ and 2.25 , respectively. At maturation, the percentage of infection for neck blast was $55.02 \%, 50.29 \%, 47.30 \%, 11.40 \%, 23.83 \%, 15.20 \%$, $16.69 \%, 16.34 \%, 12.67 \%$ and $0 \%$, respectively for the $10 \mathrm{pyr}-$ amiding lines in GZ63S background (Fig. 3). The resistance scores for the two-gene pyramiding lines C815S (Pit/Pigm), C815S (Pi5/Pit), C815S (Pi5/Pigm), C815S (Pi37/Pigm) were $3.50,4.50,3.62$ and 2.29 , respectively, for leaf blast and $4.76 \%, 22.50 \%, 22.50 \%$ and $0 \%$, respectively, for neck blast (Fig. 3). By contrast, the resistance scores of the 
Table 4 broad-spectrum resistance of resistance genes over whole growth period in 2016 in Xianfeng

\begin{tabular}{|c|c|c|c|c|c|}
\hline \multirow{2}{*}{$\begin{array}{l}\text { Recurrent } \\
\text { parent }\end{array}$} & \multirow[t]{2}{*}{ Gene } & \multicolumn{2}{|l|}{ Leaf blast } & \multicolumn{2}{|l|}{ Neck blast } \\
\hline & & Phenotypic value & PVE (\%) & Phenotypic value (\%) & PVE (\%) \\
\hline \multirow[t]{6}{*}{ Y58S } & None & 6.53 & 0 & 100.00 & 0 \\
\hline & Pid3 & 1.83 & $11.39^{*}$ & 5.15 & $16.79 * *$ \\
\hline & Pi37 & 3.90 & $13.89^{*}$ & 12.98 & $11.91^{*}$ \\
\hline & Pi54 & 3.96 & $12.30^{*}$ & 3.76 & $31.26^{* *}$ \\
\hline & Pi37 + Pid3 & 1.60 & $24.46^{* *}$ & 3.05 & $32.38^{* *}$ \\
\hline & $P i 37+P i 54$ & 3.56 & $14.48^{*}$ & 3.88 & $30.28^{* *}$ \\
\hline \multirow[t]{6}{*}{ GZ63S } & None & 7.02 & 0 & 100.00 & 0 \\
\hline & Pi5 & 3.60 & $12.84^{*}$ & 16.49 & $9.53^{*}$ \\
\hline & Pi54 & 3.73 & $9.52^{*}$ & 15.67 & $12.90^{* *}$ \\
\hline & Pid3 & 3.07 & $19.95^{* *}$ & 2.50 & $48.10^{* *}$ \\
\hline & Pi5 + Pi54 & 2.80 & $19.40^{* *}$ & 12.67 & $17.39^{* *}$ \\
\hline & Pi54 + Pid3 & 2.25 & $22.74^{* *}$ & 0.00 & $55.80^{* *}$ \\
\hline \multirow[t]{4}{*}{ C815S } & None & 6.98 & 0 & 100.00 & 0 \\
\hline & Pigm & 3.02 & $10.12^{*}$ & 6.86 & $9.27^{*}$ \\
\hline & Pi37 & 2.95 & $22.64^{* *}$ & 1.82 & $13.55^{* *}$ \\
\hline & Pigm + Pi37 & 2.29 & $24.47^{* *}$ & 0.00 & $46.37^{* *}$ \\
\hline
\end{tabular}

PVE (\%), phenotypic variation explained (\%); Significantly different from BC lines carrying blast resistance genes and corresponding recurrent parents lacking these genes at ${ }^{*} P<0.01$ and ${ }^{*} P<0.05$

recurrent parents Y58S, GZ63S and C815S were 6.53, 7.02 and 6.98, respectively, for leaf blast and the percentage of infection for neck blast was $100.00 \%, 100.00 \%$ and $100.00 \%$, respectively. These results indicate that the pyramiding lines were more strongly resistant to blast than the control.

In the background of Y58S, the leaf blast sores for Pi37, Pid3 and Pi37/Pid3 were 3.90, 1.83 and 1.60, respectively, which explained the phenotype variation of $13.89 \%, 11.39 \%$ and $24.46 \%$, respectively. The percentage of infection for neck blast for Pi37, Pid3 and Pi37/Pid3 was 12.98\%, 5.15\% and $3.05 \%$, respectively, which explained the phenotype variation of $11.91 \%, 16.79 \%$ and $32.38 \%$ (Table 4; Fig. 4). In the background of Y58S, the two-gene pyramiding line Pi37/ Pid3 showed enhanced resistance to blast compared with single gene lines for leaf and neck blast. In the background of GZ63S, the resistance to leaf blast of the two-gene pyramiding lines of Pi5/Pi54 and Pid3/Pi54 were 2.80 and 2.25, while the resistance to neck blast was $12.67 \%$ and $0 \%$, which showed significant difference from the single gene lines (Table 4; Fig. 3; Fig. 4). In the background of C815S, the leaf and neck blast of two-gene pyramiding line Pi37/Pigm were 2.29 and $0 \%$, which showed significant difference from the single gene lines (Table 4; Fig. 3). From the results above, all of the pyramiding lines showed greater resistance to blast than the single gene lines, especially for neck blast.

\section{Discussion}

Since the 1980s, several blast resistance genes have been identified and transferred into elite susceptible varieties, producing a series of improved cultivars with blast resistance. In recent years, MAS has been employed for transferring blast resistance genes to new varieties. Among the 35 cloned genes, the breeding application of blast genes Pi1 and Pi2 has often been reported (Jiang et al. 2012; Liu et al. 2012; Jiang et al. 2015; Ni et al. 2015; Tian et al. 2016), but reports of other cloned blast genes in rice were rare. Here, we introduced 9 cloned blast resistance genes-Pi37, Pit, Pid3, Pigm, Pi36, Pi5, Pi54, Pikm and Pbl-into 4 rice varieties and evaluated their applications in breeding.

In our study, the blast resistance of 9 donor parents was evaluated under natural infection conditions in 2014, 2015 and 2016. Four donor parents-Gumei4 (Pigm), Digu (Pid3), Tetep (Pi54) and Q1333 (Pi37)have high resistance to leaf and neck blast, four donor parents K59 (Pit), Tsuyuake (Pikm), Modan (Pb1) and RIL260 (Pi5) have medium or high resistance to leaf blast and susceptible to neck blast, while Q61 (Pi36) was susceptible to leaf and neck blast. From the results, we can see that the resistance of donor parents could differ even under the same infection conditions.

We used $\mathrm{BC}_{1} \mathrm{~F}_{2}$ and $\mathrm{BC}_{2} \mathrm{~F}_{2}$ populations to evaluate the effects of individual genes in different backgrounds. Additive and dominant effects were used to evaluate gene effects in $F_{2}$ population. Gene effects differed in the four rice backgrounds. The gene Pigm and Pid3 showed significantly enhanced resistance to blast in all four rice backgrounds, but the gene $\mathrm{Pbl}$ 

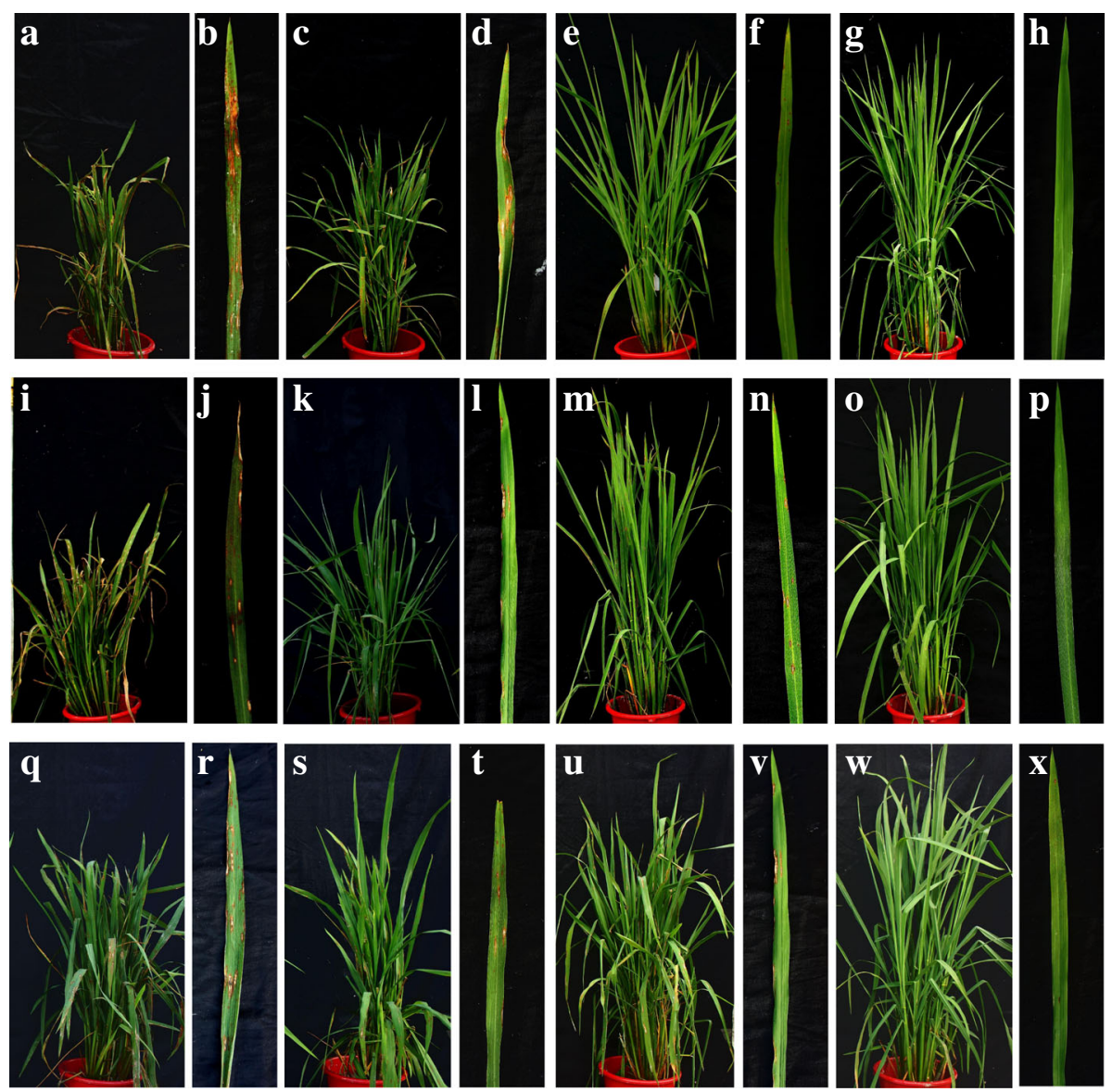

Fig. 4 Phonotypes of improved lines and controls for leaf blast under natural infection conditions. a, b Phenotype of recurrent parent Y58S for leaf blast under natural infection conditions. Phenotypes of improved plants carrying resistance gene under Y58S background to leaf blast under natural infection condition: c, d Y58S (Pi54); e, f Y58S (Pid3); $\mathbf{g}, \mathbf{h}$ Y58S (Pi54 + Pid3). i, j phenotype of recurrent parent GZ63S to leaf blast under natural infection condition. Phenotype of improved plants carrying resistance gene under GZ63S background to leaf blast under natural infection condition; k, I GZ63S (Pi54); m, n GZ63S (Pi5); o, p GZ63S (Pi54 + Pid3). q, $\mathbf{r}$ phenotype of recurrent parent C815SS to leaf blast under natural infection condition. Phenotype of improved plants carrying resistance gene under C815SS background to leaf blast under natural infection condition. s, t C815SS (Pigm); u, v C815SS (Pi37); w, $\mathbf{x}$ C815SS (Pigm + Pi37)

showed no significant difference in rice blast resistance than the control. The same gene might also perform differently in different years in the same background. The blast resistance of gene Pi54 was better in 2015 than in 2014 in the background of Y58S. The reason for this is mainly due to the different gene effects influenced by different climate or physiological factors.

From the blast resistance performance of the 9 genes in 3 years in Xianfeng, we can see that Pid3 and Pigm have better resistance than the other genes, so these two genes are valuable for application in the Wuling mountain area. Pigm have a broad-spectrum and durable resistance to rice blast that confers durable resistance to the fungus Magnaporthe oryzae without yield penalty through epigenetic regulation of paired antagonistic NBS-LRR (Deng et al. 2017). The genes Pi54, Pi37 and Pi5 should be used according to background. Genes such as $P b 1$ and Pit have little resistance to blast, mainly because the fungus Magnaporthe oryzae in Xianfeng can overcome them, so these genes are not suitable for the Xianfeng area, although they may be suitable in other areas.

Two blast resistance genes Pi54 and Pikm on rice chromosome 11 were used to improve blast resistance of the sterile lines through MAS with different markers with the distance of $\sim 2.5 \mathrm{Mb}$. Genes Pikm, $P i k-h$ and Pik-p were mapped on the Pik locus, and these genes comprised a pair of NBS-LRR genes, but gene Pi54 encodes one NBS-LRR protein. The genes Pi54, Pikm, Pik-h and Pik-p were clone from rice variety Tetep, Tsuyuauke, K3 and K60, respectively. Donor parents Tetep and Tsuyuauke were high or medium resistant to rice blast in three years, and K3 and $\mathrm{K} 60$ may have a potentially value in rice blast resistance breeding. 
Broad spectrum and durable resistance are the major objectives of rice blast resistance breeding. Most efforts in breeding for blast resistance have been directed towards incorporating single genes. Rice varieties containing only one major resistance gene have a tendency to break down as unpredictable changes occur in the composition of pathogen populations, so pyramiding more blast resistance genes in a rice cultivar may solve this problem (Ahn and Ou 1982; Kiyosawa 1982). Gene pyramiding can overlap different resistance genes, which seems promisingly to provide broad spectrum and durable resistance (Tabien et al. 2002). In this study, we developed lines containing two blast resistance genes Y58S (Pi37/Pid3), GZ63S (Pi5/Pi54), GZ63S (Pi54/Pid3) and C815S (Pigm/Pid37) that were highly resistant to leaf and neck blast under natural infection conditions, and the phenotypes showed that the effect on neck blast was better than on leaf blast in the Y58S, GZ63S and C815S backgrounds.

Most rice varieties lose their resistance after a few years planted in the same area because many varieties of single resistance genes must cope with new $M$. oryzae races. Studies have indicated that the genetic control of blast resistance is complex and involves both major and minor resistance genes with complementary or additive effects, as well as environmental interactions. Mapping new blast resistance genes and developing durable resistance varieties are, therefore, of high value. To pursue durable resistance to blast, we should exploit genetic diversity, which is an ecological approach to disease control that can be highly effective over a large area and contribute to the sustainability of crop production (Zhu et al. 2000). In this study, we introduced 9 cloned blast resistance genes into 4 recurrent parents. The effects of the genes on blast resistance were evaluated in the natural environment, and the results provide an important theoretical basis for the utilization of these rice blast resistance genes in China.

\section{Additional file}

Additional file 1: Table S1. SSR or InDel markers used for selection of blast resistance genes. (DOCX $19 \mathrm{~kb}$ )

\section{Acknowledgements}

We are very grateful to Professor Jong-Seong Jeon in Kyung Hee University, Professor Qinghua Pan in South China Agricultural University and the International Rice Genebank in IRRI for providing seeds for the donor parents of the blast resistance cultivars.

\section{Funding}

This work was supported by grants from the National Program on R\&D of Transgenic Plants (2016ZX08001002-002), the National Natural Science Foundation (31801438) and the earmarked fund for the China Agriculture Research System (CARS-01-03) of China.

\section{Availability of data and materials}

The data sets supporting the results of this article are included within the article and its supporting files.

\section{Authors' contributions}

$\mathrm{YH}$ designed the experiments. $\mathrm{HJ}, \mathrm{ZL}$, JL and $\mathrm{ZS}$ performed the experiments. GG and QZ helped with field management. HJ and ZL analyzed the data. HJ and $\mathrm{YH}$ wrote the manuscript. All authors approved the manuscript.

Ethics approval and consent to participate

Not applicable.

\section{Consent for publication}

Not applicable.

\section{Competing interests}

The authors declare that they have no competing interests.

\section{Publisher's Note}

Springer Nature remains neutral with regard to jurisdictional claims in published maps and institutional affiliations.

Received: 2 November 2018 Accepted: 18 April 2019

Published online: 06 May 2019

\section{References}

Ahn SW, Ou SH (1982) Quantitative resistance of rice to blast disease. Phytopathology 72:279-282

Ashikawa I, Hayashi N, Yamane H, Kanamori H, Wu JZ, Matsumoto T, Ono K, Yano M (2008) Two adjacent nucleotide-binding site-leucine-rich repeat class genes are required to confer Pikm-specific rice blast resistance. Genetics 180(4):2267

Ashikawa I, Wu JZ, Matsumoto T, Ishikawa R (2010) Haplotype diversity and molecular evolution of the rice Pikm locus for blast resistance. J Gen Plant Pathol 76(1):37-42

Chen S, Wang L, Que ZQ, Pan RQ, Pan QH (2005) Genetic and physical mapping of $P i 37(t)$, a new gene conferring resistance to rice blast in the famous cultivar St. no. 1. Theor Appl Genet 111(8):1563-1570

Deng YW, Zhai KR, Xie Z, Yang DY, Zhu XD, Liu JZ, Wang X, Qin P, Yang YZ, Zhang GM, Li Q, Zhang JF, Wu SQ, Milazzo J, Mao BZ, Wang E, Xie H, Tharreau D, He ZH (2017) Epigenetic regulation of antagonistic receptors confers rice blast resistance with yield balance. Science 355(6328):962

Deng YW, Zhu XD, Xu J, Chen HQ, He ZH (2009) Map-based cloning and breeding application of a broad-spectrum resistance gene Pigm to rice blast. In: Wang X, Valent B (eds) Advances in genetics, genomics and control of Rice blast Disease. Springer, New York

Hayashi K, Yoshida H (2009) Refunctionalization of the ancient rice blast disease resistance gene Pit by the recruitment of a retrotransposon as a promoter. Plant J 57(3):413-425

Hayashi N, Inoue H, Kato T, Funao T, Shirota M, Shimizu T, Kanamori H, Yamane H, Hayano-Saito Y, Matsumoto T, Yano M, Takasuji H (2010) Durable panicle blast-resistance gene Pb1 encodes an atypical CC-NBS-LRR protein and was generated by acquiring a promoter through local genome duplication. Plant J 64(3):498-510

IRRI (2002) Standard Evaluation System for Rice. IRRI, Manila

Jiang HC, Feng YT, Bao L, Li X, Gao GJ, Zhang QL, Xiao JH, Xu CG, He YQ (2012) Improving blast resistance of $\mathrm{Jin} 23 \mathrm{~B}$ and its hybrid rice by marker-assisted gene pyramiding. Mol Breed 30:1679-1688

Jiang JF, Mou TM, Yu HH, Zhou FS (2015) Molecular breeding of thermo-sensitive genic male sterile (TGMS) lines of rice for blast resistance using Pi2 gene. Rice 8(1):11

Kiyosawa S (1982) Genetics and epidemical modeling of breakdown of plant disease resistance. Annu Rev Phytopathol 20:93-117

Koide Y, Kobayashi N, Xu DH, Fukuta Y (2009) Resistance genes and selection DNA markers for blast disease in rice (Oryza sativa L.). JARQ-Jap Agr Res Q 43:255-280

Lee SK, Song MY, Seo YS, Kim HK, Ko S, Cao PJ, Suh JP, Yi G, Roh JH, Lee S, An G, Hahn TR, Wang GL, Ronald P, Jeon JS (2009) Rice Pi5-mediated resistance to Magnaporthe oryzae requires the presence of two coiled-coil-nucleotidebinding-leucine-rich repeat genes. Genetics 181(4):1627

Lin F, Chen S, Que ZQ, Wang L, Liu XQ, Pan QH (2007) The blast resistance gene Pi37 encodes a nucleotide binding site leucine-rich repeat protein and is a member of a resistance gene cluster on rice chromosome 1. Genetics 177(3):1871 
Liu JL, Wang XJ, Mitchell T, Hu YJ, Liu XL, Dai LY, Wang GL (2010a) Recent progress and understanding of the molecular mechanisms of the rice and Magnaporthe oryzae interaction. Mol Plant Pathol 11:419-427

Liu WG, Wang F, Liu ZR, Zhu XY, Li JH, Huang HJ, Liao YL, Zhu MS, Fu CY, Chen JW (2012) Improvement of rice blast resistance in CMS line Rongfeng a by pyramiding Pi-1 and Pi-2 with molecular marker techniques. Mol Plant Breed 10(5):575-582

Liu XQ, Ling W, Liu XD, Liu XQ, Wang DB, Wang CT, Lin F, Pang QH (2010b) The molecular evolution of the rice blast resistance gene Pi36. Int J Plant Sci 171(3):235-243

Liu XQ, Wang L, Chen S, Lin F, Pan QH (2005) Genetic and physical mapping of $\mathrm{Pi} 36(t)$, a novel rice blast resistance gene located on rice chromosome 8 . Mol Gen Genomics 274(4):394-401

Ni DH, Song FS, Ni JL, Zhang AF, Wang CL, Zhao KJ, Yang YC, Wei PC, Yang JB, Li $L$ (2015) Marker-assisted selection of two-line hybrid rice for disease resistance to rice blast and bacterial blight. Field Crops Res 184:1-8

Ramkumar G, Srinivasarao K, Mohan KM, Sudarshan I, Sivaranjani AKP, Gopalakrishna K, Neeraja CN, Balachandran SM, Sundaram RM, Prasad MS, Rani NS, Prasad AMR, Viraktamath BC, Madhav MS (2011) Development and validation of functional marker targeting an InDel in the major rice blast disease resistance gene Pi54 (Pik ${ }^{h}$ ). Mol Breed 27(1):129-135

Shang JJ, Tao Y, Chen XW, Zou Y, Lei CL, Wang J, Li XB, Zhao XF, Zhang MJ, Lu ZK, Xu JC, Cheng ZK, Wan JM, Zhu LH (2009) Identification of a new rice blast resistance gene, Pid3, by genomewide comparison of paired nucleotide-binding site-leucine-rich repeat genes and their pseudogene alleles between the two sequenced rice genomes. Genetics 182(4):1303-1311

Sharma TR, Rai AK, Gupta SK, Singh NK (2010) Broad-spectrum blast resistance gene Pi-k $K^{h}$ cloned from rice line Tetep designated Pi54. J Plant Biochem Biotechnol 19(1):87-89

Sharma TR, Shanker P, Singh BK, Jana TK, Madhav MS, Gaikwad K, Singh NK, Plaha $P$, Rathour R (2005) Molecular mapping of rice blast resistance gene $P i-K^{h}$ in the rice variety Tetep. J Plant Biochem Biotechnol 14(2):127-133

Su J, Wang WJ, Han JL, Chen S, Wang CY, Zeng LX, Feng AQ, Yang JY, Zhou B, Zhu XY (2015) Functional divergence of duplicated genes results in a novel blast resistance gene Pi50 at the Pi2/9 locus. Theor Appl Genet 128(11):2213-2225

Sun GC, Cai RY, Du XF, Tao RX, Sun SY (1999) The directional selection and stabilizing selection from the interaction between rice variety and blast fungus Magnaporthe grisea. Acta Phytopathol Sinica 29:45-49

Tabien RE, Li Z, Paterson AH, Marchetti MA, Stansel JW, Pinson SRM (2002) Mapping QTLs for field resistance to the rice blast pathogen and evaluating their individual and combined utility in improved varieties. Theor Appl Genet 105:313-324

Tanksley SD, Young ND, Paterson AH, Bonierbale MW (1989) RFLP mapping in plant breeding: new tools for old science. Biotechnol 7:257-264

Tian HG, Chen HQ, Hu J, Zhu XD, Qian Q (2016) Transmitted three genes by marker-assisted selection to improve rice blast resistance of Kongyu131. J Nucl Agric Biol 30(11):2096-2103

Vasudevan K, Gruissem W, Bhullar NK (2016) Corrigendum: identification of novel alleles of the rice blast resistance gene Pi54. Sci Rep 6(15678):17920

Wang BH, Daniel JE, Wang ZH (2017) The arms race between Magnaporthe oryzae and rice: diversity and interaction of Avr and $R$ genes. J Integr Agric 16(12):2746-2760

Wu KS, Tanksley SD (1993) PFGE analysis of the rice genome: estimation of fragment sizes, organization of repetitive sequences and relationships between genetic and physical distances. Plant Mol Biol 23(2):243-254

Xiao N, Wu YY, Pan CH, Yu L, Chen Y, Liu GQ, Li YH, Zhang XX, Wang ZP, Dai ZY, Liang CZ, Li AH (2017) Improving of rice blast resistances in japonica by pyramiding major R Genes. Front Plant Sci 7:1918

Yuan B, Zhai C, Wang WJ, Zeng XS, Xu XK, Hu HQ, Lin F, Wang L, Pan QH (2011) The Pik-p resistance to Magnaporthe oryzae in rice is mediated by a pair of closely linked CC-NBS-LRR genes. Theor Appl Genet 122(5):1017-1028

Zhai C, Zhang Y, Yao N, Lin F, Liu Z, Dong ZQ, Wang L, Pan QH (2014) Function and interaction of the coupled genes responsible for Pik-h encoded rice blast resistance. PLoS One 9(6):e98067

Zheng WJ, Wang Y, Wang LL, Ma ZB, Zhao JM, Wang P, Zhang LX, Liu ZH, Lu XC (2016) Genetic mapping and molecular marker development for Pi65(t), a novel broad-spectrum resistance gene to rice blast using next-generation sequencing. Theor Appl Genet 129(5):1035-1044

Zhu YY, Chen HR, Fan JH, Wang YY, Li Y, Chen JB, Fan JX, Yang SS, Hu LP, Leung H, Mew TW, Teng PS, Wang ZH, Mundt CC (2000) Genetic diversity and disease control in rice. Nature 406(6797):718-722

\section{Submit your manuscript to a SpringerOpen ${ }^{\circ}$ journal and benefit from:}

- Convenient online submission

- Rigorous peer review

- Open access: articles freely available online

High visibility within the field

- Retaining the copyright to your article

Submit your next manuscript at $\boldsymbol{\nabla}$ springeropen.com 